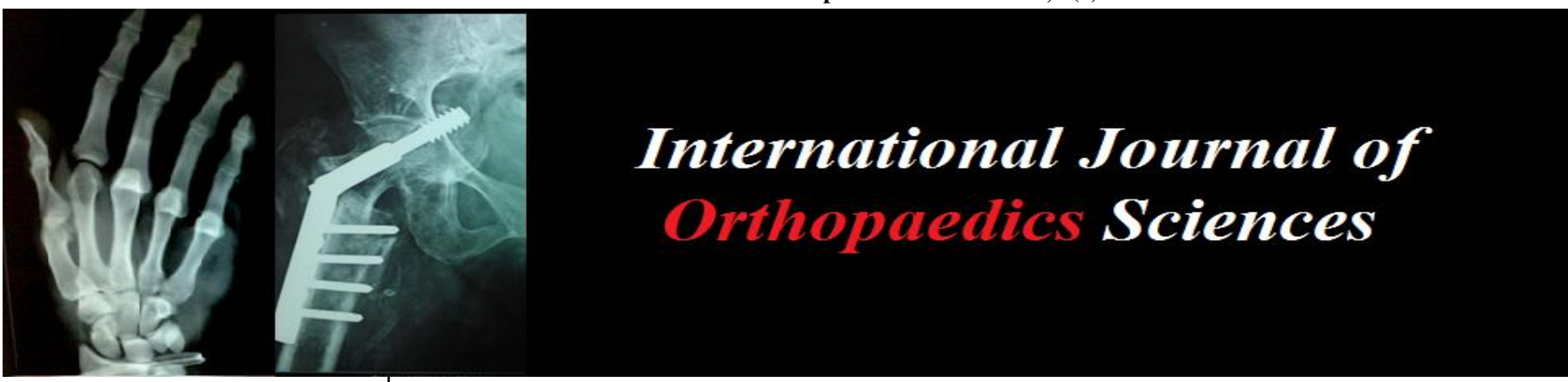

ISSN: $2395-1958$

IJOS 2018; 4(1): 1012-1017

(C) 2018 IJOS

www.orthopaper.com

Received: 24-11-2017

Accepted: 25-12-2017

Ansari Muqtadeer Abdul Aziz Associate Professor, Department of Orthopaedics, Government Medical College Aurangabad, Maharashtra, India

\section{Dr. Rahul Gopikishan Jaju}

Assistant Professor, Department of Orthopaedics, Government Medical College Aurangabad,

Maharashtra, India

Vishal Bahua

Ex Resident Doctor, Lokmanya Tilak Medical College, Mumbai Maharashtra, India

\section{CJ Thakkar}

Ex Professor and Unit Head, Department of Orthopaedics, LTMMC, Mumbai, Maharashtra India
Correspondence

Dr. Rahul Gopikishan Jaju Assistant Professor, Department of Orthopaedics, Government Medical College, Aurangabad, Maharashtra, India

\section{Incidence of femoro-acetabular impingement in adult Indian population on the basis of specific radiological findings: A prospective study}

\author{
Ansari Muqtadeer Abdul Aziz, Rahul Gopikishan Jaju, Vishal Bahua and \\ CJ Thakkar
}

DOI: https://doi.org/10.22271/ortho.2018.v4.i10.144

\begin{abstract}
Introduction: Femoroacetabular impingement is a major cause of early osteoarthritis of the hip, especially in young and active patients. It is characterized by an early pathologic contact during hip joint motion between acetabulum and femur that limits the physiologic hip range of motion,. Depending on clinical and radiographic findings, it can be pincer or cam type. Most patients (86\%) have a combination of both forms. The role of imaging in femoroacetabular impingement is to evaluate the hip for abnormalities associated with impingement and to exclude arthritis, avascular necrosis, or other joint problems on radiographs.

Materials and Methods: Between August 2010 and November 2010, 100 radiographs of pelvis with both hips and both hips lateral view of normal subjects were obtained and included in this study. All radiographic parameters of interest in the present study were assessed by three observers including one radiologist. The intraobserver and interobserver coefficients for the various parameters, assessed on a sub-set of fifty radiographs, ranged from 0.90 to 0.98 which was significant. All the 100 sets of 3 x-rays were studied in this manner.

Discussion: The aim of our study was to determine the prevalence of femoroacetabular impingement in Indian population. Western countries have a proportionally higher rate of primary osteoarthritis of hip. It is increasingly coming to notice that radiographs of idiopathic osteoarthritis of hip show signs of femoroacetabular impingement. Therefore, there could be a causal association between femoroacetabular impingement and idiopathic osteoarthritis of hip.

Conclusion: Femoroacetabular impingement is recognized condition causing hip pain in young active adults and is believed to be a cause of hip osteoarthritis. Further studies are still required to evaluate the nature of disease process, its natural history, actual cause and effect relationship between femoroacetabular impingement and osteoarthritis.
\end{abstract}

Keywords: Femoroacetabular, pincer, cam, osteoarthritis

\section{Introduction}

Osteoarthritis of the hip is a debilitating and painful condition affecting a substantial proportion of the population. Idiopathic osteoarthritis accounts for approximately $40 \%$ to $50 \%$ of all cases of degenerative arthritis ${ }^{[1-3]}$, and a growing body of literature supports the hypothesis that idiopathic osteoarthritis is frequently caused by subtle, and often radiographically occult, abnormalities at the femoral head-neck junction or acetabulum that result in abnormal contact between the femur and the acetabulum ${ }^{[4-9]}$. This condition, known as femoroacetabular impingement, has been proposed as the leading cause of labral tears, as well as degenerative hip arthritis. The structural abnormalities associated with femoroacetabular impingement were noted several decades ago ${ }^{[1,3,10]}$ when abnormalities of the femoral head-neck contour were referred to as tilt or pistol grip deformities, which Ganz et al. ${ }^{[11,12]}$ classified as cam morphology. In addition, Ganz et al. identified another mechanism of femoroacetabular impingement known as pincer, which is secondary to acetabular overcoverage of the femoral head and is present in a third of the patients with a cam deformity. Most patients (86\%) have a combination of both forms of impingement, which is called "mixed pincer and cam impingement," with only a minority (14\%) having the pure femoroacetabular 
impingement forms of either cam or pincer impingement ${ }^{[13]}$. Pincer impingement is more common in middle-aged women, occurring at an average age of 40 years ${ }^{[14]}$, and can occur with various disorders. A normal acetabulum is anteverted and has the anterior rim line projected medially to the posterior wall line. A focal overcoverage of the anterosuperior acetabulum causes a cranially retroverted acetabulum. This is defined with the anterior rim line being lateral to the posterior rim in the cranial part of the acetabulum and crossing the latter in the distal part of the acetabulum. This configuration is called the "cross-over" sign ${ }^{[15]}$. Through observations at the time of open hip surgery, Ganz et al. defined the mechanisms of cartilage damage associated with femoroacetabular impingement as well as its clinical and radiographic features $[8,11]$. However, with any new diagnosis, it is important that the diagnostic criteria be accurate and reproducible in order to properly assess the efficacy of different treatments as well as the natural course of the disease. Although the association of femoro-acetabular impingement with hip osteoarthritis is well-known, little is known about the distribution of these malformations in a population-based setting or the magnitude of related clinical problems. Previous population-based risk estimates of the development of osteoarthritis have focused solely on acetabular dysplasia. There are very few studies which have documented the prevalence of femoro-acetabular impingement in adult population in any part of the world, let alone India. The main purpose of this study is to see whether femoroacetabular impingement is as significant a problem in Indian population as in western population.

\section{Materials and Methods}

Between August 2010 and November 2010, 100 radiographs of pelvis with both hips and both hips lateral view of normal subjects were obtained from the department of Radiology in LTMGH hospital and included in this study. Approval of Ethics committee was taken and informed consent of the subjects was taken. Patients in the age group of 16 to 50 years were included in the study. Patients with age less than 16 years or more than 50 years, whose Radiographs showing osteoarthritic changes in hip and those who are willing to give consent were excluded from the study. Standard radiographic technique was used to take radiographs. Antero-posterior views were taken with the patient supine with both lower limbs internally rotated 15 degrees to better visualise the contour of the femoral head and neck. Standard uniform film to tube distance of 1.2 metres was used; the central beam was directed to the midpoint between a line connecting both anterosuperior iliac spines and the superior border of the symphysis, which can easily and reproducibly be palpated by the radiology technician._Cross table lateral view, also known as the Danelius-Miller View was taken. The $\mathrm{x}$-ray tube was then turned so that it would shoot across the table (thus giving us the name cross table lateral) and angled so that the x-rays it produces will be perpendicular to the $\mathrm{x}$-ray film. The patient was then helped to raise the opposite leg with the hip and knee flexed to 90 degrees and the foot resting on a helper specially made for the purpose. The affected lower extremity was rotated internally for 15 degrees then the $\mathrm{x}$-ray was quickly taken with film to tube distance of 1.2 metres (Figure 1)

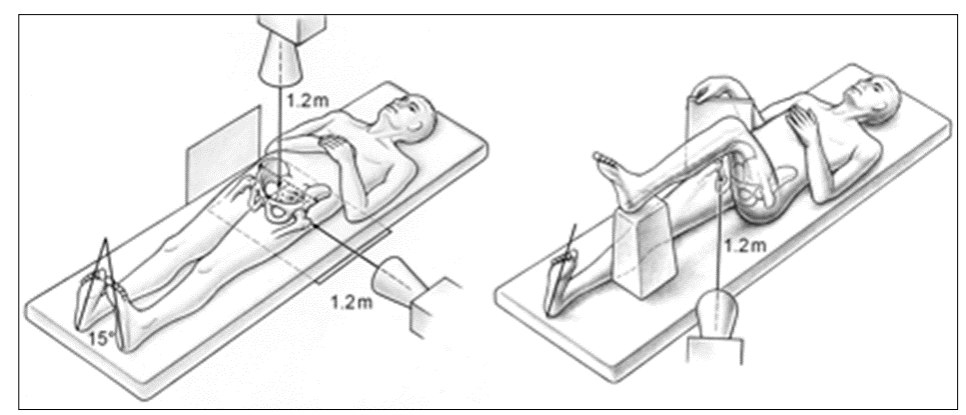

Fig 1

All radiographic parameters of interest in the present study were assessed by three observers including one radiologist. The intraobserver and interobserver coefficients for the various parameters, assessed on a sub-set of fifty radiographs, ranged from 0.90 to 0.98 which was significant. All the 100 sets of 3 x-rays were studied in this manner and the various parameters were calculated and noted. For determining the centre of femoral head a special template of concentric circles out-lined on a piece of transparent material also known as Moses' template was used (Figure 2).

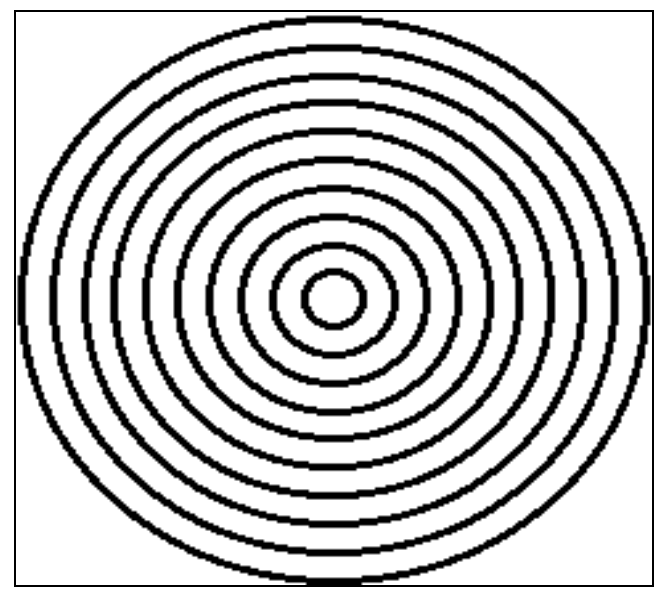

Fig 2 
Following signs of pincer impingement were looked radio graphically

\section{A. Lateral centre edge angle of WIBERG (Figure 3)}

The centre-edge angle was first described by Wiberg in 1939 . It is formed by the intersection of a line drawn through the midpoint of the femoral head and a second line drawn from the centre of the femoral head to the upper outer margin of the acetabulum. The centre-edge angle is one of the most commonly used uniplanar discriminators of acetabular dysplasia and a deep acetabular socket. Increasing age has been shown to influence the centre edge angle. To compensate for the age related increase of centre-edge angle, an excessive centre-edge angle is considered to be pathological when it is more than 45 Degrees ${ }^{[16]}$.

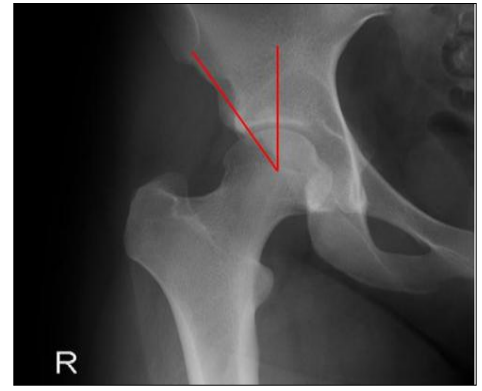

Fig 3

\section{B. Acetabular index (Figure 4)}

The angle between the line joining the inner edge of acetabulum and the outer edge with the horizontal is the acetabular index. It is positive in normal individuals. It becomes negative as acetabulum deepens Schematic and radiographic representation of normal hip and positive acetabular index.

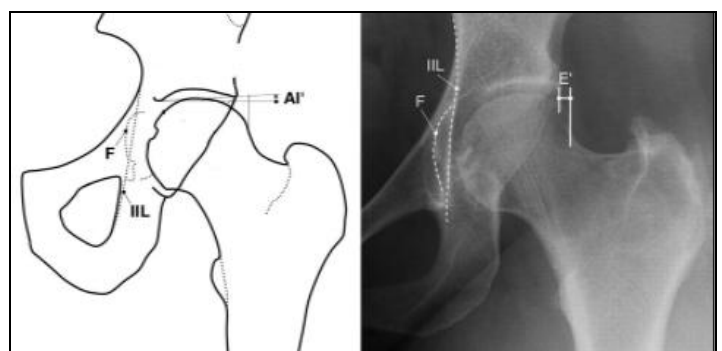

Fig 4: IIL-Ilio-Ischial line AI-Acetabular index E'- femoral head extrusion

\section{Acetabular extrusion index (Figure 5)}

The femoral head extrusion index, expresses the percentage of the femoral head diameter uncovered by the acetabulum, or the percentage of the femoral head lateral from Perkin's line. Cut-off value set at $25 \%$. Any value less than $25 \%$ suggests pincer type of impingement.

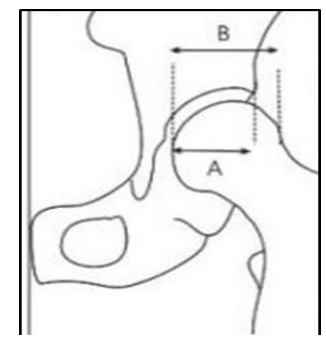

Fig 5: Extrusion index $=\frac{B-A}{B}$

\section{Posterior wall sign (Figure 6)}

Posterior wall line should pass exactly through the centre of the femoral head, If it passes laterally, then it is suggestive of pincer type of impingement, If the line passes medially, then it is suggestive of cam type of impingement.

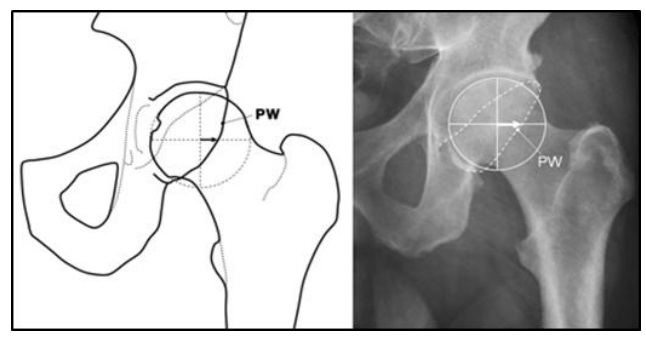

Fig 6

\section{E. Os Acetabuli (Figure 7)}

Small accessory ossicles at the lateral margin of the acetabulum develop due to constant wear and tear. These accessory ossicles are known as os acetabuli.

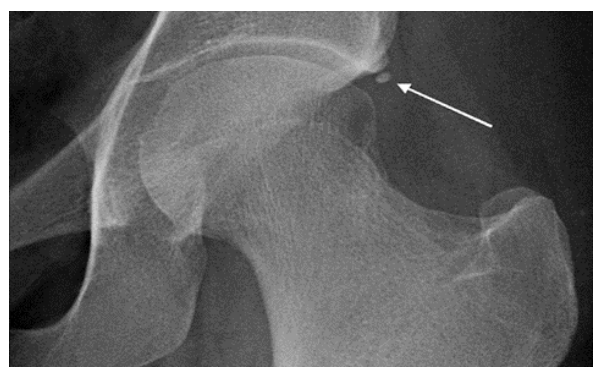

Fig 7

\section{E. Linear indentation sign (Figure 8)}

In pincer hips, corresponding linear indentation often occurs on femoral side with reactive cortical thickening, which can be seen on conventional radiograph and on MR arthrogram with intra-articular contrast agent. It is seen on cross-table lateral radiograph. It occurs due to mechanical damage to the cartilage at that point and reactionary cortical bone thickening.

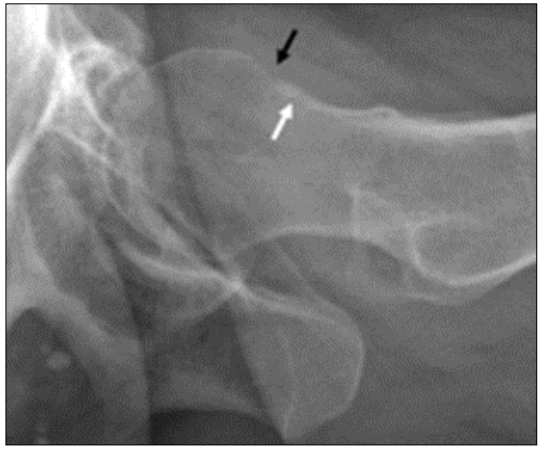

Fig 8

Following signs of cam impingement were looked radio graphically

\section{F. Pistol grip deformity (Figure 9)}

Pistol grip deformity occurs usually in cam type of FAI. Due to the loss of concavity, which is normally present at the antero-superior margin of the femoral head, on plain radiographs it looks like the rear end of the pistol. It may also be seen rarely in fracture healing, Perthe`s disease, slipped capital femoral epiphysis. 


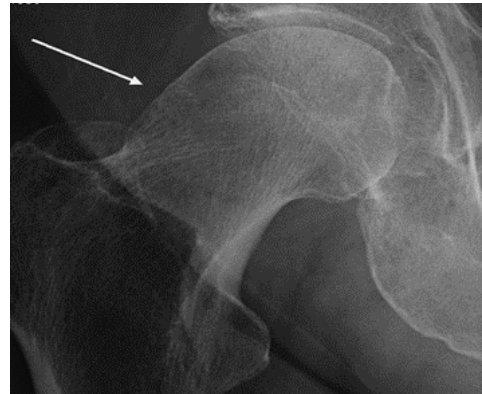

Fig 9

\section{G. Alpha angle (Figure 10)}

It is quantitative measure of the asphericity of the femoral head. Alpha angle is the angle between the femoral neck axis and a line connecting the head center with the point of beginning asphericity of the head-neck contour. On the basis of cadaveric studies, it has been found that alpha angle more than 55 degrees predisposes significantly to labral damage during extreme range of movements. Hence alpha angle is considered abnormal if it is more than 55 degrees ${ }^{[17]}$.

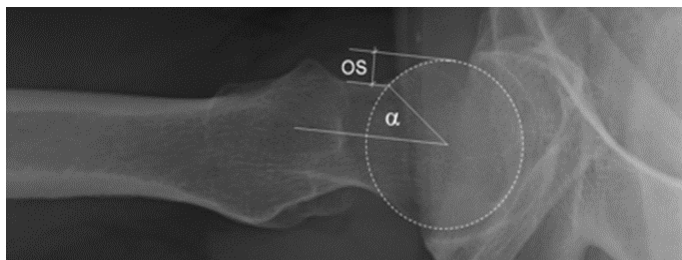

Fig 10

\section{H. Anterior femoral off-set (Figure 11)}

Another parameter for quantification of cam impingement is the anterior femoral offset, which is defined as the difference in radius between the anterior femoral head and the anterior femoral neck on a cross-table axial view of the proximal femur. It is considered abnormal if it is less than $10 \mathrm{~mm}$.

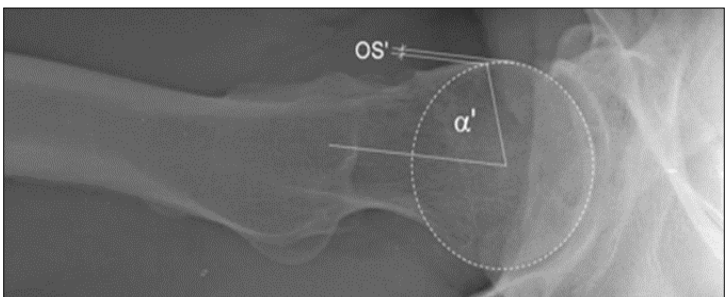

Fig 11

After calculating the various parameters, subjects were classified into 4 groups

- Normal group

- Pincer group

- Cam group

- Mixed (Cam + pincer) group

\section{Results}

100 sets of 3 radiographs (PBH-AP and bilateral hip lateral) were available for analysis in our study for calculating the incidence of femoroacetabular impingement in adult Indian population. There were 51 males and 49 females. The agewise distribution of patients was as follows (Table 1)

Table 1: The age-wise distribution of patients

\begin{tabular}{|c|c|}
\hline Age in years & Percent \\
\hline $15-20$ & 7 \\
\hline $20-25$ & 12 \\
\hline $25-30$ & 19 \\
\hline $30-35$ & 17 \\
\hline $35-40$ & 20 \\
\hline $40-45$ & 11 \\
\hline $45-50$ & 14 \\
\hline
\end{tabular}

Since we studied both sides of all subjects our sample size was 200 hips. Out of those 200 hips we identified 10 hips to be abnormal in 5 patients. 4 subjects showed both cam and pincer type of impingement whereas 1 subject showed only pincer type of impingement. The prevalence of cam + pincer type of impingement was $5 \%$ which was statistically significant $(\mathrm{p}<.01 \%)$. The prevalence of isolated pincer type of impingement was $1 \%$. The mean lateral centre edge angle was 38 degrees with a standard deviation of 3.8 degrees. The mean femoral head extrusion index was 0.31 with a standard deviation of 0.04 .

\section{Following is the graphical representation of various parameters}

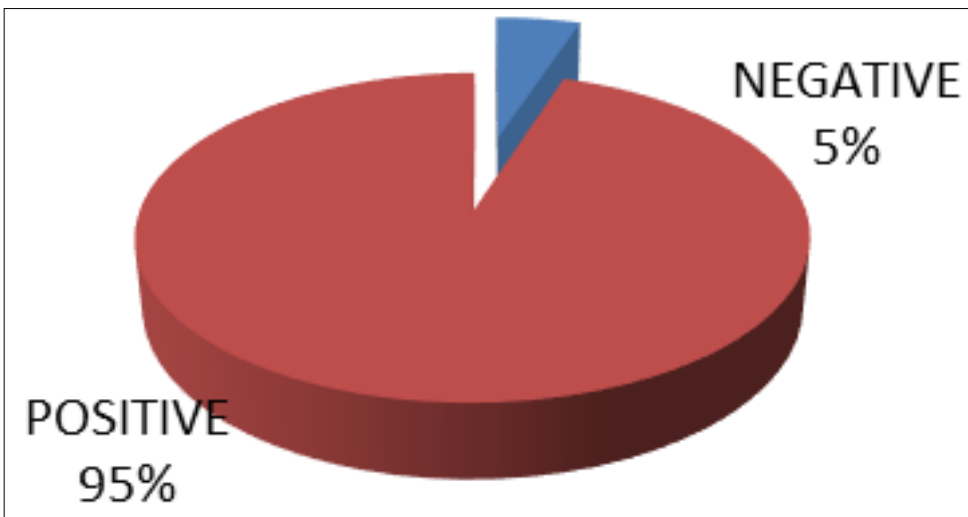

Graph 1: A negative Acetabular index in 5\% of patients suggestive of pincer type of impingement 


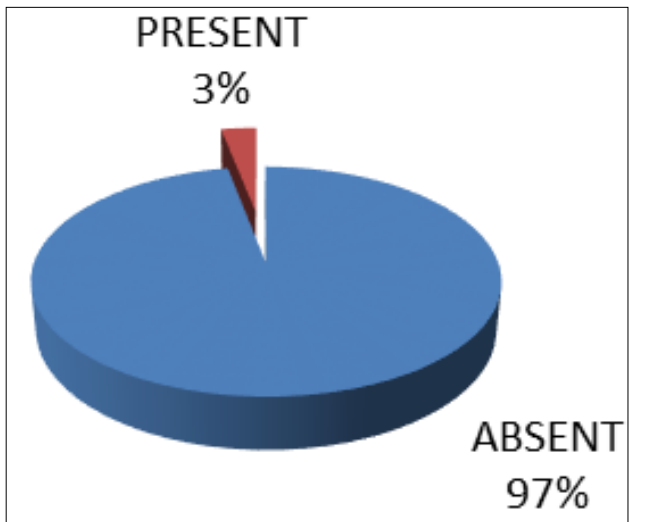

Graph 2: Os acetabuli were present in 3 percent of cases

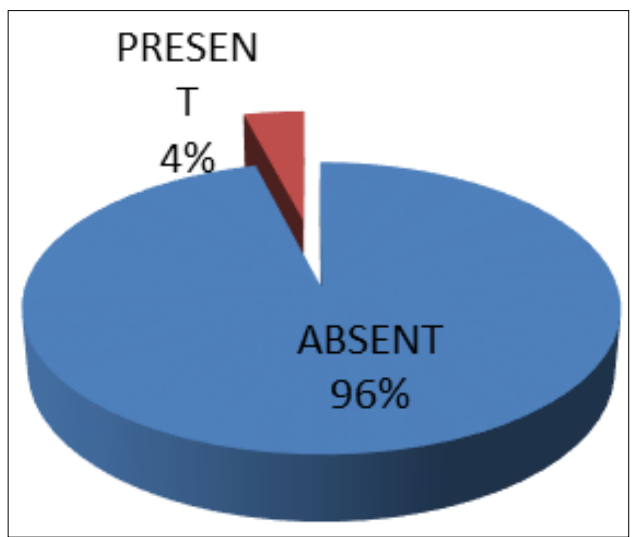

Graph 3: Pistol-grip deformity present in $4 \%$ of cases

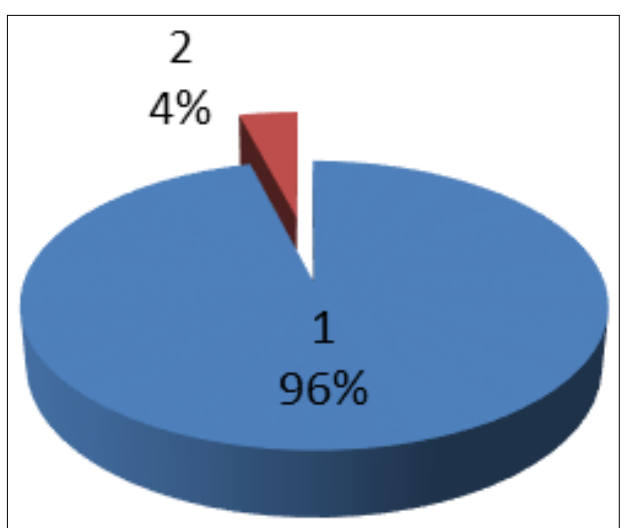

Graph 4: Alpha angle more than 55 degrees was noted in $4 \%$ of cases

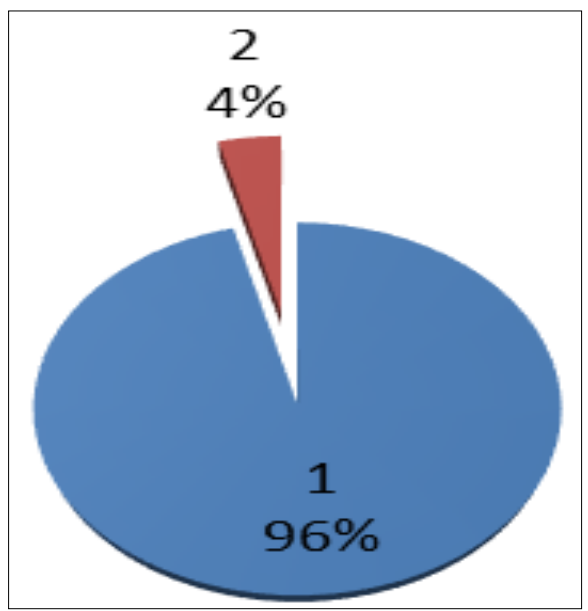

Graph 5: Femoral off-set of less than $10 \mathrm{~mm}$ was found in $4 \%$ of cases
Case 1

\section{3 year old female}

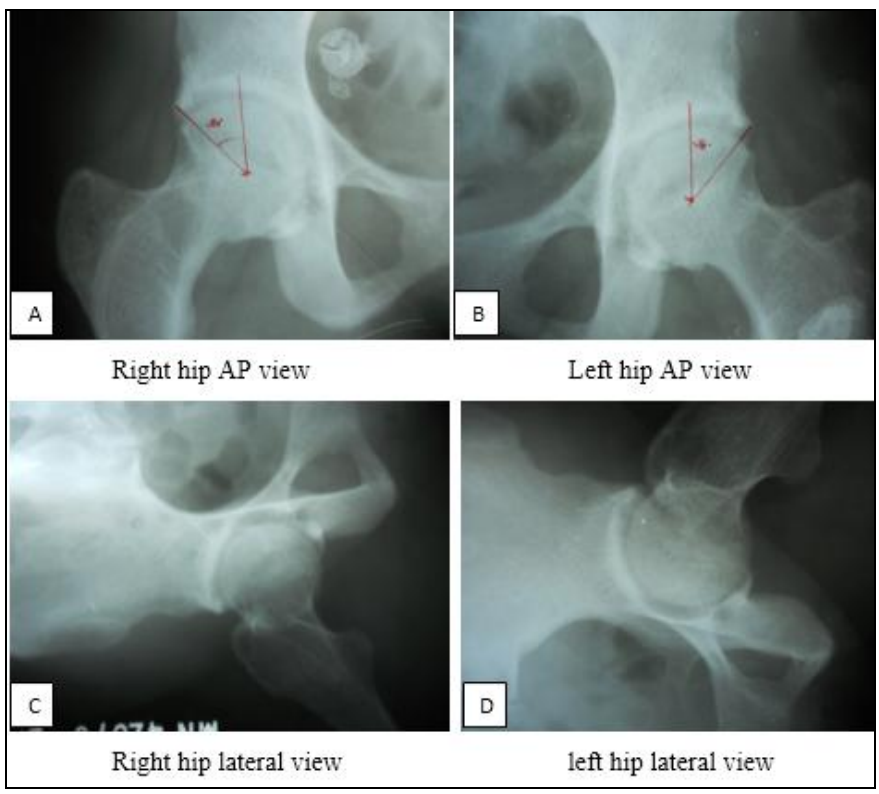

Fig 12

\section{Discussion}

Femoroacetabular impingement has been implicated as an etiologic factor for both acetabular labral pathology and idiopathic arthritis of the hip. The proposed mechanism of labral cartilage damage is excessive shear stresses caused by abnormal osseous contact within the hip joint as a result of the abnormal contour of the femoral head-neck junction (insufficient femoral head-neck offset or cam impingement) or acetabular over coverage (pincer impingement)._To our knowledge, this cross-sectional study is the first population based study of incidence of femoro-acetabular impingement in India. The main strengths of our study are the simplicity and the standardization of radiographs according to a protocol. The major weakness of our study is the crosssectional design which limits the assessment of cause and effect relationships. Other weaknesses include the size of cohort of about 200 hips which may not be enough to generalize the incidence to a larger population. Also the quality of radiographs did not allow us to visualise the acetabular rims and measure the version of the acetabular socket. The centre-edge angle of Wiberg is one of the most commonly used uniplanar discriminators of deep acetabular socket. Increasing age has been shown to influence the centre edge angle. In our study, since we included patients with age upto fifty years, we took a centre-edge angle of 45 degrees as the cut-offfor pincer impingement. There is still some confusion in literature as to the exact limits of normal centreedge angle. Some studies have taken 40 degrees as the cut-off limit of centre-edge angle whereas some others have taken 45 degrees. We have taken 45 degrees as the cut-off because there is a strong correlation between centre-edge angle of more than 45 degrees and significant hip pain due to labral tears. Thus there is still some obscurity as to the normal limits of centre-edge angle which need to be refined further.

The aim of our study was to determine the prevalence of femoro-acetabular impingement in Indian population. There has been no prior study conducted in India for femoroacetabular impingement. Western countries have found the incidence to be $8-15 \%$. Studies in Japan have found the incidence to be $0.6 \%$ in Japan. We found the incidence in our 
study to be in the intermediate range at $5 \%$. This discrepancy can be explained by the differences in the prevalence of osteoarthritis of hips in both countries. Western countries have a proportionally higher rate of primary osteoarthritis of hip. It is increasingly coming to notice that radiographs of idiopathic osteoarthritis of hip show signs of femoroacetabular impingement. Indeed according to one study upto $71 \%$ of cases of idiopathic osteo-arthritis of hip show pistolgrip deformity. Therefore, there could be a causal association between femoro-acetabular impingement and idiopathic osteo-arthritis of hip and further studies are required for the same.

\section{Summary and Conclusion}

Femoro-acetabular impingement is an increasingly recognized condition causing hip pain in young active adults and is believed to be a cause of hip osteo-arthritis. It describes a pathologic abutment between the femoral head and the acetabular rim. There are no large-scale studies to determine the magnitude of the disease problem in the general population in India. Our study is an observational study which shows a statistically significant $5 \%$ prevalence of femoroacetabular impingement in India. There are very few available studies to compare the incidence with Western countries where the estimated prevalence is $8-15 \%$. Further studies are still required to evaluate the nature of disease process, its natural history, actual cause and effect relationship between femoro-acetabular impingement and osteo-arthritis as well as better definition of its various parameters.

\section{References}

1. Murray RO. The aetiology of primary osteoarthritis of the hip. Br J Radiology. 1965; 38:810 24.

2. Solomon L. Patterns of osteoarthritis of the hip. J Bone Joint Surg Br. 1976;58:176-83

3. Stulberg SD, Cordell LD, Harris WH, Ramsey PL, MacEwen GD. Unrecognized childhood hip disease: a major cause of idiopathic osteoarthritis of the hip. In: Amstutz HC, editor. The hip. Proceedings of the Third Open Scientific Meeting of the Hip Society. St. Louis: CV Mosby, 1975, 212-28.

4. Leunig M, Casillas MM, Hamlet M, Hersche O, N*otzli $\mathrm{H}$, Slongo $\mathrm{T}$, et al. Slipped capital femoral epiphysis: early mechanical damage to the acetabular cartilage by a prominent femoral metaphysis. Acta Orthop Scand. 2000; 71:370-5.

5. Tanzer M, Noiseux N. Osseous abnormalities and early osteoarthritis: the role of hip impingement. Clin Orthop Relat Res. 2004; 429:170-7.

6. N”otzli HP, Wyss TF, Stoecklin CH, Schmid MR, Treiber K, Hodler J. The contour of the femoral headneck junction as a predictor for the risk of anterior impingement. J Bone Joint Surg Br. 2002; 84:556-60.

7. Ito $\mathrm{K}$, Minka MA, Leunig $\mathrm{S}$, Werlen $\mathrm{S}$, Ganz $\mathrm{R}$. Femoroacetabular Impingement and the cam-effect. A MRI-based quantitative anatomical study of the femoral head-neck offset. J Bone Joint Surg Br. 2001; 83:171-6.

8. Beck M, Kalhor M, Leunig M, Ganz R. Hip morphology influences the pattern of damage to the acetabular cartilage: femoroacetabular impingement as a cause of early osteoarthritis of the hip. J Bone Joint Surg Br. 2005; 87:1012-8.

9. Wenger DE, Kendell KR, Miner M, Trousdale RT. Acetabular labral tears rarely occur in the absence of bony abnormalities. Clin Orthop Relat Res. 2004;
426:145-50

10. Resnick D. The 'tilt deformity' of the femoral head in osteoarthritis of the hip: a poor indicator of previous epiphysiolysis. Clin Radiol. 1976; 27:355-63.

11. Ganz R, Parvizi J, Beck M, Leunig M, N“otzli HP, Siebenrock KA. Femoroacetabular impingement: a cause for osteoarthritis of the hip. Clin Orthop Relat Res. 2003; 417:112-20.

12. Kassarjian A, Yoon LS, Belzile E, Connolly SA, Millis MB, Palmer WE. Triad of MR arthrographic findings in patients with cam-type femoroacetabular impingement. Radiology. 2005; 236:588-92.

13. Beck M, Kalhor M, Leunig M, Ganz R. Hip morphology influences the pattern of damage to the acetabular cartilage: femoroacetabular impingement as a cause of early osteoarthritis of the hip. J Bone Joint Surg Br. 2005; 87:1012-1018.

14. Moritz Tannast, Klaus A Siebenrock, Suzanne E. Anderson Femoroacetabular Impingement: Radiographic Diagnosis-What the Radiologist Should Know. AJR. 2007; 188:1540-1552

15. Siebenrock KA, Kalbermatten DF, Ganz R. Effect of pelvic inclination on determination of acetabular retroversion: a study on cadaver pelves. Clin Orthop Relat Res. 2003; 407:241-248.

16. Kasper Kjaerulf Gosvig, Steffen Jacobsen, Stig Sonne-H olm, Henrik Palm and Anders Troelsen J Bone Joint Surg Am. 2010; 92:1162-1169. doi:10.2106/JBJS.H.01674.

17. Zilber S, Lazennec JY, Gorin M, Saillant G. Variations of caudal, central and cranial acetabular anteversion according to the tilt of the pelvis. Surg Radiol Anat. 2004; 26:462-465 